\title{
LO QUE COLOMBIA PUEDE APRENDER DE TAILANDIA SOBRE POLÍTICA DE DROGAS
}

Vanda Felbab-Brown*

T a dramática expansión del cultivo de coca en Colombia ejerce Lgran presión sobre su gobierno para que reduzca la producción. Esa presión proviene de políticos colombianos de derecha, de políticos estadounidenses inclinados a la guerra contra las drogas y de organismos internacionales antinarcóticos. Pero la erradicación prematura de la coca y los esfuerzos antidrogas mal diseñados pueden significar un desastre para el acuerdo de paz con las Fuerzas Armadas Revolucionarias de Colombia (FARC), y para la paz social en general que el país tiene oportunidad de lograr.

La producción estimada de cocaína en Colombia aumentó en un $37 \%$ desde 2015, hasta un máximo histórico de 710 toneladas en 2016. Hay muchas hipótesis a ese respecto: las FARC alientan a los agricultores a cultivar más coca desde las protestas cocaleras de 2013; los agricultores conocen el plan del gobierno colombiano bajo el acuerdo de paz con las FARC de compensar a los cultivadores por el cambio a cultivos legales; el fin de la fumigación aérea por la preocupación de que el glifosato sea cancerígeno; la falta de medios de subsistencia alternativos (pues la supresión anterior solo se logró mediante la erradicación o la interdicción), y el declive de precios de materias primas como la madera y el oro, a cuya extracción se dedicaron algunos cocaleros.

* Senior Fellow, Foreign Policy, Center for $21^{\text {st }}$ Century Security and Intelligence. Tomado de Order from chaos, blog de la Brookings Institution, 4-052017. Se publica con las autorizaciones correspondientes. Traducción de Alberto Supelano. Fecha de recepción: 8-05-2017, fecha de aceptación: 04-09-2017. Sugerencia de citación: Felbab-Brown, V. (2017). "Lo que Colombia puede aprender de Tailandia sobre política de drogas", Revista de Economía Institucional 19(37), 323-327. Dor: https://doi.org/10.18601/01245996.v19n37.15 
En respuesta, el gobierno colombiano y el acuerdo post paz con las FARC declararon conjuntamente en enero el muy ambicioso objetivo de eliminar 50 mil hectáreas de coca este año mediante un esfuerzo de "sustitución del cultivo" compensado voluntariamente, una vieja terminología para referirse a lo que se espera llegue a ser un desarrollo rural más integral. Entre finales de enero y finales de marzo se han inscrito unas 58 mil familias con 2.016 parcelas que cubren unas 49 mil hectáreas de coca. Después de erradicarla recibirán compensación y ayuda del gobierno para conseguir títulos de sus tierras. El gobierno también planea eliminar otras 50 mil hectáreas mediante erradicación forzada, no compensada, en los parques nacionales y reservas indígenas del país.

Es digno de elogio dar prioridad a la supresión de coca en áreas protegidas. Pero la erradicación voluntaria compensada y el esquema de sustitución del cultivo están plagados de escollos y peligros.

\section{DE NUEVO, ¿UNA SECUENCIACIÓN EQUIVOCADA?}

La historia de los medios de subsistencia alternativos en Colombia es en su mayor parte una historia de fracasos. Una de las razones es el problema de la secuenciación: los funcionarios insisten en la erradicación, a menudo hasta cero hectáreas, incluso antes de establecer medios de subsistencia alternativos. Pero el enfoque "primero la erradicación, después los medios de subsistencia alternativos", nunca ha funcionado en Colombia, ni siquiera con las mejores intenciones y mucho esfuerzo, como en Nariño. Esto se debe a que los medios de subsistencia alternativos suelen tomar años de esfuerzo multifacético para arraigar y empezar a producir ingresos suficientes y sostenibles. Insistir en la erradicación como condición previa - la cual no se materializa en ingresos suficientes- emponzoña todo esfuerzo de los agricultores.

En comparación con esfuerzos similares anteriores, el nivel de compensación es hoy mucho mayor: 7.800 dólares en el primer año, quizá 12 mil dólares por familia en dos años, para un total de unos 340 millones de dólares dedicados a medios de subsistencia alternativos. La compensación de esfuerzos anteriores, incluido el programa Guardabosques para eliminar el cultivo de coca en parques nacionales, solo llegaba a unos cientos de dólares por familia. Suma que quizá cubría la seguridad alimentaria de una familia durante algunos meses, pero no dejaba lo suficiente para la inversión necesaria en medios de subsistencia legales. Pero incluso con esta mayor compensación, insistir en la erradicación previa como precondición de la ayuda al 
desarrollo es riesgoso y contraproducente. Por fortuna, parece dar al menos algún margen, pues las comunidades no están obligadas a erradicar toda su coca antes de recibir una compensación; aun así, dos años es un lapso demasiado corto.

Tolerar que los agricultores cultiven coca en una pequeña porción de sus tierras durante algunos años permitiría desarrollar medios de subsistencia alternativos. Una pequeña parcela de coca puede proporcionar un seguro esencial a una familia mientras intenta pasar a una alternativa, y protege sus ingresos contra las grandes fluctuaciones de precios de los cultivos legales. La política boliviana de un cato, muy controversial pero efectiva, sirve de ejemplo. En Washington, por supuesto, se sigue considerando a Bolivia como un paria, porque recientemente se duplicó la cantidad de tierra en la que los agricultores pueden cultivar legalmente coca para usos tradicionales, aunque persisten las fugas del cultivo legal hacia el comercio ilegal de cocaína.

Otro error típico es centrarse excesivamente en cultivos sustitutos como el café o el cacao, y subestimar la infraestructura de apoyo al desarrollo y las cadenas de valor agregado. También es esencial desarrollar oportunidades de trabajo no agrícolas e invertir en programas básicos de desarrollo humano para cocaleros y potenciales cocaleros.

\section{EL MODELO DE TAILANDIA}

Tailandia es amplia y merecidamente reconocida como el modelo sobre cómo reducir cultivos ilícitos mediante programas integrales de medios de subsistencia alternativos. También fue uno de los primeros países que aprendió, en los años sesenta y setenta, que para derrotar a la insurgencia era necesario suspender las políticas punitivas de supresión del cultivo de drogas.

Hay varios elementos en el éxito de Tailandia. Las políticas de erradicación del cultivo de drogas se suspendieron durante las operaciones de contrainsurgencia y durante algunos años del posconflicto, mientras se iniciaban los programas de medios de subsistencia alternativos en las zonas de cultivo de amapola. La erradicación se suspendió hasta que los medios de subsistencia alternativos generaron ingreso suficiente a los cultivadores de adormidera, no antes ni simultáneamente, como se suele prescribir en los esfuerzos internacionales contra el narcotráfico. La adormidera solo empezó a ser erradicada después de varios años de intentos de establecer medios de subsistencia alternativos, y la erradicación se negoció en gran medida con las comunidades locales, a menudo a través de un comité mixto gobierno-comunidad que determinaba si se generaban suficientes ingresos legales. 
Los medios de subsistencia alternativos fueron bien diseñados, como desarrollo rural integral, y no solo se centraron en la sustitución de ingresos sino también en un desarrollo más amplio del capital humano y en la reducción de la marginación social y política de las minorías étnicas que cultivaban adormidera. Los trabajadores del desarrollo se comprometieron firmemente con las familias cultivadoras de amapola durante años y años. El enfoque simplista original de buscar cultivos sustitutos -cebolla, ajo, col o productos más valiosos como el albaricoque- fue complementado gradualmente por el enfoque del desarrollo socioeconómico y del capital humano más amplio, incluido el mejoramiento de la conectividad de la infraestructura, la construcción de cadenas de valor agregado, y la extensión de atención médica y escuelas a áreas productoras de opio.

Las políticas también fueron bien financiadas y mantenidas durante treinta años, recibiendo firme apoyo de la familia real y de algunos socios internacionales clave, como la agencia de desarrollo alemana.

Sin embargo, las condiciones en Tailandia eran sumamente auspiciosas. El cultivo de drogas era limitado: de hecho, de una magnitud inferior a la de muchos otros países que deben enfrentar el cultivo de drogas. En general, solo cubría unas 10 mil hectáreas de amapola, y alcanzó el máximo en 1965 cuando se cultivaron unas 18 mil hectáreas de adormidera. Esa es una pequeña fracción de las 159 mil hectáreas cultivadas en Colombia en 2015.

Algo esencial fue que la economía de Tailandia también creció notablemente en los años ochenta y comienzos de los noventa, creando muchas oportunidades de trabajo, incluido el empleo no agrícola. Los agricultores de las tierras bajas pasaron a trabajar en fábricas de las ciudades, liberando oportunidades de agricultura legal para las minorías cultivadoras de opio en tierras altas. E1 turismo floreciente en las zonas montañosas creó más oportunidades no agrícolas, mientras que la creciente densidad de población alentó aún más a la población de las tierras altas a explorar oportunidades no agrícolas. El hecho de que la ciudadanía y los títulos de propiedad de las tierras también se extendieran a las minorías cultivadoras de amapola fue esencial para su capacidad de aprovechar las nuevas oportunidades económicas.

La estrategia dio frutos. En 2002 Tailandia fue declarada libre de drogas, y se convirtió en el único país que ha eliminado cultivos ilícitos mediante enfoques de medios de subsistencia predominantemente alternativos. 


\section{LOS MUCHOS RETOS DE COLOMBIA}

E1 desarrollo rural no será fácil en Colombia: requerirá muchos recursos, tiempo y capacidad política. Todos son difíciles de conseguir, y lo serán aún más si un político uribista gana las elecciones presidenciales de Colombia en 2018. El éxito también requiere que el gobierno colombiano enfrente los intereses creados opuestos al desarrollo rural más equitativo y a una mayor inclusión, a pesar de las promesas del acuerdo de paz con las FARC. Entre las medidas necesarias está la tarea muy sensible y exigente de modificar el sistema tributario: hoy la tierra está muy poco gravada, lo que alienta el robo de tierras y la concentración de la propiedad, incluido el lavado de dinero, y además permite que la tierra se mantenga ociosa. Por otra parte, el trabajo es gravado fuertemente, lo que alienta el crecimiento intensivo en capital en vez de la tan necesaria creación de empleos legales.

Además, algunas zonas están demasiado alejadas para que cualquier proyecto agrícola legal sea rentable. En esas zonas, la coca persistirá; y en ese caso, la única solución sería la reubicación de personas. Dada la historia colombiana de brutal desplazamiento interno y robo de tierras, será crucial asegurar que tal reubicación sea verdaderamente voluntaria.

Colombia también debería aprender la lección negativa de Tailandia, y, a ese respecto, de la mayoría de los esfuerzos de medios de subsistencia alternativos de todo el mundo, incluida su historia reciente. A menudo la economía sustitutiva fue la tala de bosques y la minería-legales e ilegales-que provocan una deforestación masiva y la degradación del medio ambiente. Colombia debería empeñarse resueltamente en evitar las experiencias anteriores y actuales de Myanmar, Bolivia y Perú, y emprender un desarrollo alternativo que preserve y no destruya su enorme diversidad natural. Es alentador que al menos un esfuerzo de desarrollo, patrocinado por la agencia alemana de desarrollo, hoy trate de hacer eso. Pero es un paso demasiado pequeño hacia lo que se necesita.

Y, por último, el éxito dependerá de la seguridad; frente a las unidades disidentes de las FARC y de otras guerrillas de izquierda como el Ejército de Liberación Nacional (eln) y el Ejército Popular de Liberación (EPL), y fundamentalmente, frente a las muchas y fuertes bandas criminales, todas las cuales están involucradas en el comercio ilegal de drogas. Se debe llevar la presencia del Estado de manera robusta y legítima, bien sea llevándola desde arriba hacia abajo y quizá muy a menudo desde abajo hacia arriba. 